University of Wollongong

Research Online

Faculty of Engineering - Papers (Archive)

Faculty of Engineering and Information

Sciences

$1-1-2009$

\title{
The effects of shear stress on the lubrication performances of oil film of large-scale mill bearing
}

Zhengyi Jiang

University of Wollongong, jiang@uow.edu.au

A K. Tieu

University of Wollongong, ktieu@uow.edu.au

Jianmei Wang

University of Wollongong

Q.X. Huang

Taiyuan University of Science and Technology

Follow this and additional works at: https://ro.uow.edu.au/engpapers

Part of the Engineering Commons

https://ro.uow.edu.au/engpapers/2887

\section{Recommended Citation}

Jiang, Zhengyi; Tieu, A K.; Wang, Jianmei; and Huang, Q.X.: The effects of shear stress on the lubrication performances of oil film of large-scale mill bearing 2009, 713-718.

https://ro.uow.edu.au/engpapers/2887

Research Online is the open access institutional repository for the University of Wollongong. For further information contact the UOW Library: research-pubs@uow.edu.au 


\title{
The Effects of Shear Stress on the Lubrication Performances of Oil Film of Large-scale Mill Bearing
}

\author{
Jianmei Wang ${ }^{1, a}$, Qingxue Huang ${ }^{1, b}$, Zhengyi Jiang ${ }^{2, \mathrm{c}}$, Kiet A. Tieu ${ }^{2, \mathrm{~d}}$ \\ ${ }^{1}$ Taiyuan University of Science and Technology, People's Republic of China \\ ${ }^{2}$ University of Wollongong, Australia

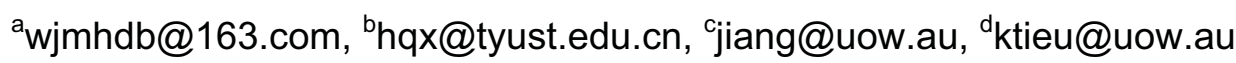

\begin{abstract}
Keywords: Oil film bearing. Finite difference method. Boundary element method. Shear stress Lubrication performance. Viscosity
\end{abstract}

\begin{abstract}
A new coupling numerical algorithm has been developed to integrate Finite Difference Method (FDM) with Boundary Element Method (BEM) to analyze shear performance of oil film by iteratively solving a series of equations such as the film flow velocity and shear stress equations for contact bodies in bearing system. With consideration of the variations of viscosity and density with pressure and temperature, the effects of shear stress of oil film layers on lubrication performance of contact surfaces under different loadcases were discussed. Moreover, Germany-made Anton Paar MRD (Magnetic Rheologic Device) was used to determine the relationship between the viscosity and shear stress of lubricating oil. The conclusions were verified to be beneficial to the further study on lubricating performance of heavy contact components and to prolong their service lives.
\end{abstract}

\section{Introduction}

To prolong the service life of large-scale heavy bearing, theoretical and experimental research has to be comprehensively done for overall assessment on on-line bearing. Not only complete check and on-line test should be made, but also the influence of temperature rise on lubricating performance of bearing should be taken into account to analyze the effects of all the factors on bearing performance, thus more refined lubrication theory could be summarized [1].

The function of oil film is to reduce friction force, but it always produces tangential force to hinder movement [2,3]. Even if the friction force is reduced to the minimum, the existing friction consumption could still decrease machinery efficiency [4,5]. Shear stress of oil film is correlated with film flow velocity. It is the perquisite to calculate the friction resistance between the shear stress and contact bodies. So, the effects of shear stress of oil film in mill bearing has been theoretically analyzed in detail, which has great meaning to further understand and grasp the lubricating performance of contact components under heavy load, as well as to prolong the bearing service life.

Calculating Model on Shear Stress of Lubricating Film. When oil-film bearing works, the lubricating oil will be brought into the wedge clearance to form into hydraulic film by the rotation of roll neck. Fig.1 shows the coordinate system of Reyonlds equation. During the whole calculation process, bearing was regarded as elastic body 1, roll as elastic body 2 and bearing chock as elastic body 3. Meanwhile, it is supposed that the rotating roll and still bearing had no axial misalignment.

Mathematical Model on Shear Stress of Lubricating Film. Shear stress formula can be deduced from the definition of Newtonian fluid.

$$
\tau_{x}=\eta \frac{\partial u}{\partial z}, \quad \tau_{y}=\eta \frac{\partial v}{\partial z}
$$

According to the rotation relationship between the bearing and the roll [6], velocity boundary conditions can be expressed as below, where $U_{0}, U_{h}$ are respectively the velocity components in $x$ direction at $z=0$ and $z=h$. 


$$
\begin{aligned}
& z=0, u=U_{0}, v=\omega=0 \\
& z=h, u=U_{h}, v=\omega=0
\end{aligned}
$$

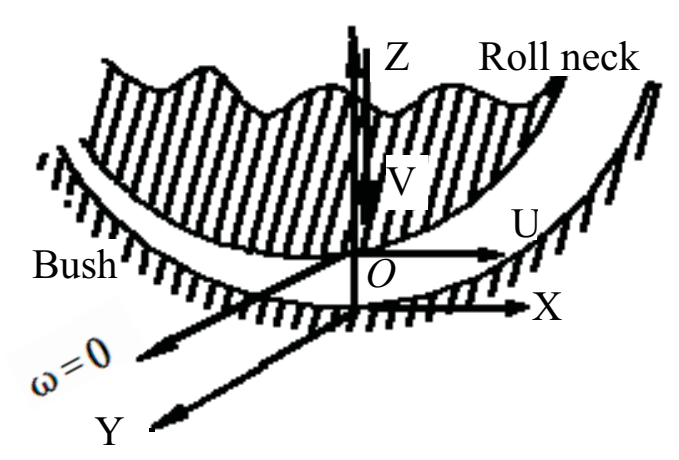

Fig. 1 Generalized coordinates for Reynolds

Neglecting the influence of curvature, setting the viscosity along the film thickness as a constant, the fluid velocity on contact surface is equal to the velocity of contact body. Bearing was fixed to bearing chock by position pin, and roll neck is supposed to have no axial misalignment, so $U_{0}=0$, $V_{h}=V_{0}=0$, then the fluid velocity in $x$ and $y$ directions at any point of lubricating film can de deduced as follows.

$$
u=U_{h} \frac{z}{h}, \quad v=\frac{1}{2 \eta} \mathrm{g} \frac{\partial P}{\partial y}\left(z^{2}-z h\right)
$$

Where $u$ is mainly consisted of the shear flow velocity defined as $u_{s}=U_{h} \frac{z}{h}$.

The velocity gradient along the film thickness is far greater than those in axial and circumferential directions, so the velocity gradient can be deduced below.

$\frac{\partial u}{\partial z}=\frac{U_{h}}{h}, \frac{\partial v}{\partial z}=\frac{1}{2 \eta} \mathrm{g} \frac{\partial P}{\partial y}(2 z-h)$

Substitute Eq. 4 into Eq. 1, then

$$
\tau_{x}=\frac{1}{2} \frac{\partial p}{\partial x}(2 z-h)+\frac{\eta}{h} U_{h}, \quad \tau_{y}=\frac{1}{2} \frac{\partial p}{\partial y}(2 z-h)
$$

On roll neck surface $z=h$, the shear stress can be deduced below.

$$
\tau_{x}=\frac{h}{2} \frac{\partial p}{\partial x}+\frac{\eta}{h} U_{h}, \quad \tau_{y}=\frac{h}{2} \frac{\partial p}{\partial y}
$$

On bearing surface $z=0$, the shear stress can be deduced below.

$$
\tau_{x}=-\frac{h}{2} \frac{\partial p}{\partial x}+\frac{\eta}{h} U_{h}, \quad \tau_{y}=-\frac{h}{2} \frac{\partial p}{\partial y}
$$

Dimensionless Mathematical Model. Substituting the following dimensionless parameters into the above equations, $\bar{X}=x / R, \quad \bar{Y}=y L / 2, \bar{P}=P h_{0}{ }^{2} / \eta_{0} u_{0} R, \quad \bar{h}=h / h_{0}, e=\delta \cdot \varepsilon, \bar{\eta}=\eta / \eta_{0}, \bar{v}=v / u_{0}$, $\bar{u}=u / U_{h}, \bar{\tau}_{x}=h_{0} \tau_{x} / \eta_{0}, \bar{\tau}_{y}=h_{0} \tau_{y} / \eta_{0}$, then the dimensionless shear stress equations can be deduced.

On roll neck surface $z=h$, the dimensionless shear stress can be deduced below.

$$
\bar{\tau}_{x}=\frac{u_{0} \bar{h}}{2} \frac{\partial \bar{p}}{\partial \bar{X}}+\frac{\bar{\eta}}{\bar{h}} U_{h}, \quad \bar{\tau}_{y}=u_{0} \bar{h} \frac{\partial \bar{p}}{\partial \bar{Y}}
$$

On bearing surface $z=0$, the dimensionless shear stress can be deduced below. 


$$
\bar{\tau}_{x}=-\frac{u_{0} \bar{h}}{2} \frac{\partial \bar{p}}{\partial \bar{X}}+\frac{\bar{\eta}}{\bar{h}} U_{h}, \quad \bar{\tau}_{y}=-u_{0} \bar{h} \frac{\partial \bar{p}}{\partial \bar{Y}}
$$

Main Input Parameters. Table 1 shows the main working and geometrical parameters of bearing, and the main parameters of lubricant are shown in Table 2.

Table 1 Main parameters of oil-film bearing

\begin{tabular}{lc}
\hline Name & Value \\
Bearing diameter $[\mathrm{mm}]$ & 1115 \\
Length-to-diameter ratio $[\mathrm{mm}]$ & 0.75 \\
Relative clearance & $0.4 \% 0^{-3 \%}$ \\
Elastic modulus $\left[\mathrm{Kg} / \mathrm{cm}^{2}\right]$ & $2.1 \times 10^{6}$ \\
Poisson ratio & 0.3 \\
Initial temperature $\left[{ }^{\circ} \mathrm{C}\right]$ & 45 \\
\hline
\end{tabular}

Table 2 Main parameters of lubricants

\begin{tabular}{lc}
\hline Name & Value \\
Viscosity $\left(40^{\circ} \mathrm{C}\right)[\mathrm{Pa} \cdot \mathrm{s}]$ & 0.41216 \\
Density $\left[\mathrm{kg} / \mathrm{m}^{3}\right]$ & 896 \\
Specific heat $[\mathrm{J} / \mathrm{kg} \cdot \mathrm{K}]$ & 2000 \\
Thermal conductivity $[\mathrm{W} / \mathrm{m} \cdot \mathrm{K}]$ & 0.14 \\
Viscosity-pressure coefficient $\left[\mathrm{m}^{2} / \mathrm{N}\right]$ & $2.2 \times 10^{-8}$ \\
Inlet oil pressure $[\mathrm{MPa}]$ & 0.12 \\
\hline
\end{tabular}

Calculating Results on Shear Stress of Lubricating Film. The dimensionless shear stress of oil-film bearing is mainly circumferential shear stress $\bar{\tau}_{x}$ and axial shear stress $\bar{\tau}_{y}$. The dimensionless shear stress on the bearing surface $\bar{Z}=0$ and roll surface $\bar{Z}=1$ at different velocity is respectively shown in Figs. 2-3. The circumferential shear stress on both contact surfaces could increase rapidly with the roll velocity, since such shear stress generally includes the shear stress by pressure flow and the shear stress by shear flow. With the improvement of roll velocity, more and more lubricating oil will be brought into wedge clearance, and the shear stress by shear flow is far larger than that by pressure flow. So, the circumferential shear stress is mainly determined by the shear flow, because the film viscosity increases rapidly when the oil film pressure increases with velocity.
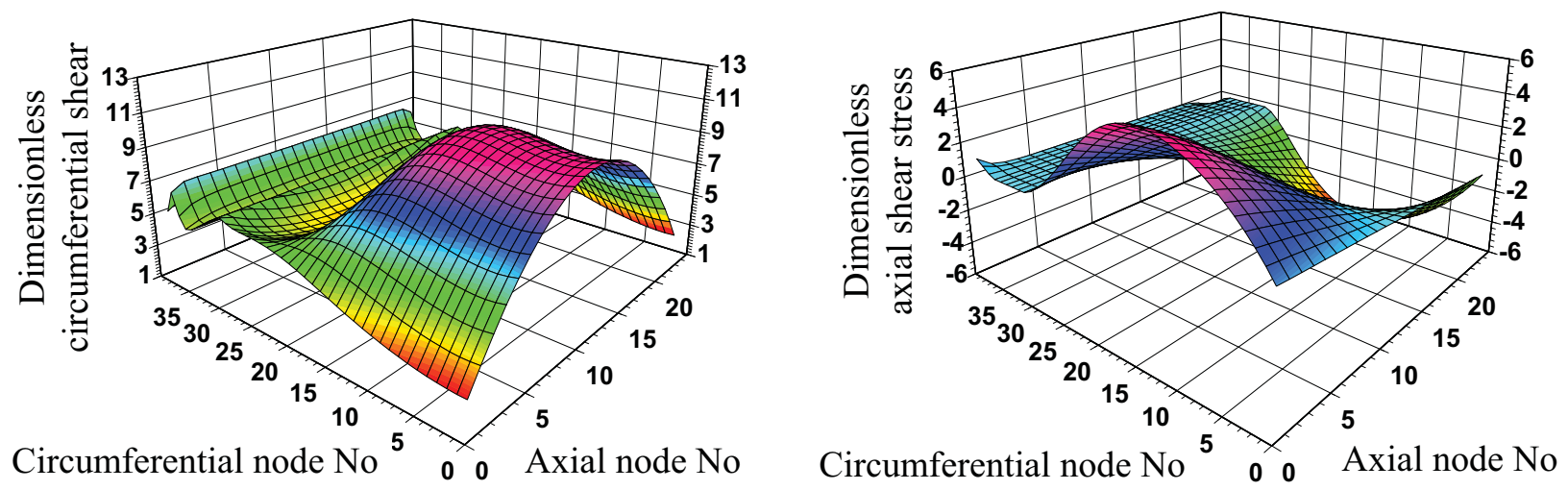

(a) Dimensionless circumferential shear stress at 20 rps (b) Dimensionless axial shear stress at 20 rps
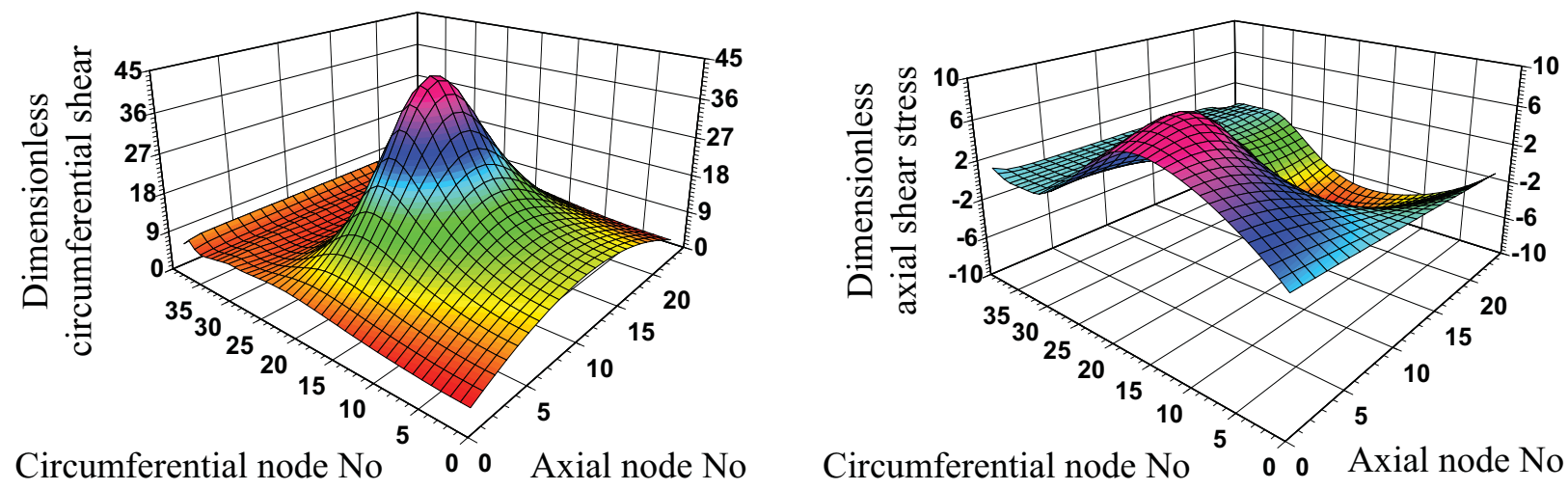

(c) Dimensionless circumferential shear stress at 50 rps (d) Dimensionless axial shear stress at 50 rps

Fig. 2 The circumferential and axial shear stresses of oil film at bearing surface $\bar{Z}=0$ 
It can be seen from above, the roll rotates and the bearing is fixed, the oil flow on bearing surface at the transient region from oil inlet zone to pressure peak zone needs to overcome larger oil film resistance, so a larger axial shear stress is required. Meanwhile, the oil flow from pressure peak zone to oil film rupture zone can be accelerated with pressure, so a smaller axial shear stress of oil film is needed.
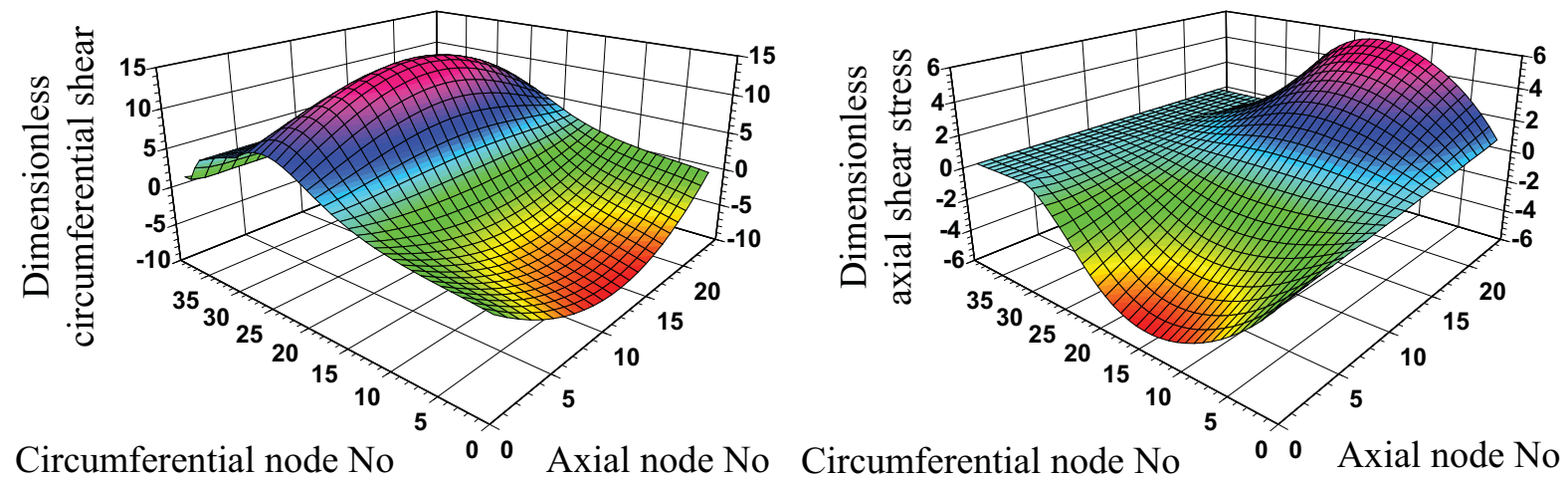

Circumferential node No

Axial node No

Circumferential node No

(b) Dimensionless axial shear stress at 20rps
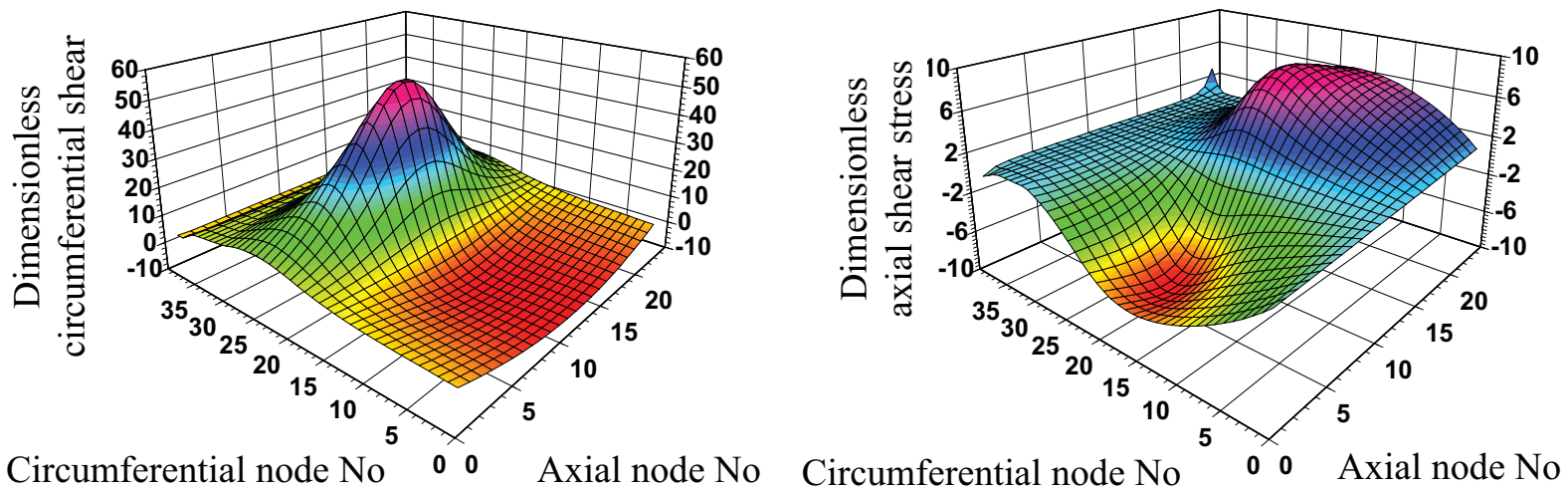

(c) Dimensionless circumferential shear stress at 50rps (d) Dimensionless axial shear stress at 50rps

Fig. 3 The circumferential and axial shear stress of oil film interface at roll surface $\bar{Z}=1$

As shown in Fig. 4, the rotation of roll makes the distribution laws of axial shear stress of oil film at different region justly contrary to the above explanation in Figs. 2-3.

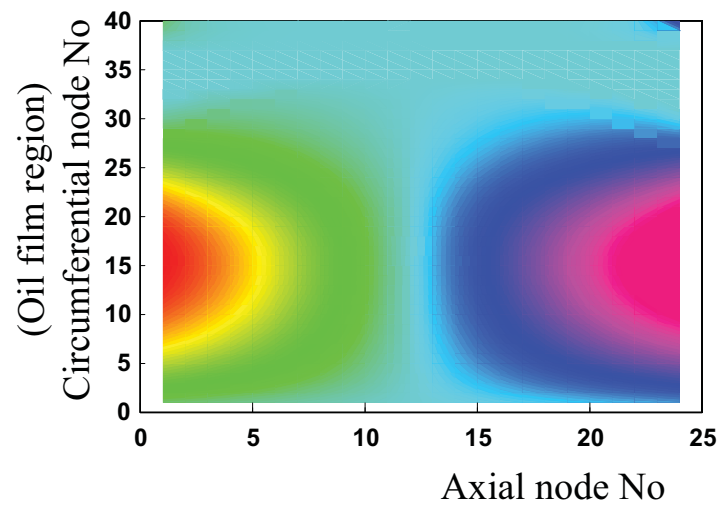

(a) Symmetry feature of spectrum profile

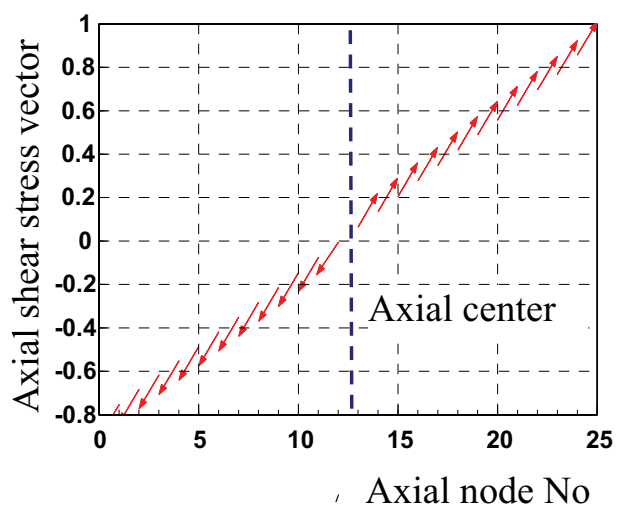

(b) Asymmetry feature of vector plot

Fig. 4 The distribution features of axial shear stress on roll surface $\bar{Z}=1$

Here, the axial shear stress of oil film is only determined by pressure flow, which generally increases with the roll velocity. At the same time, the axial shear stress on both contact surfaces 
displays asymmetry feature along the cross section of axial center, as shown in Fig. 4, and the distribution feature of axial shear stress on the roll surface and bearing surface is contrary to each other. Therefore, the rapid increasing shear stress would worsen the stress state of materials, then result in microcrack, and then fasten the expansion of crack, ultimately result in pitting damage on materials.

Measurement on Property Parameters of Oil Film. Germany-made Anton Paar Magneto Rheological Device MRD-301 was used to measure the oil film property parameters such as the viscosity and shear stress, which could provide theoretical references to further analysis on lubricating film performance of oil-film bearing in large-scale mill.

The Variation of Oil Film Shear Stress Under Different Film Thickness. As shown in Fig.5, the viscosity of lubricating oil decreases with an increase of temperature, and the shear stress to overcome the lubricating oil flow also obviously decreases as the temperature increases. Moreover, the shear stress of oil film under no normal stress decreases with a decrease of oil film thickness.
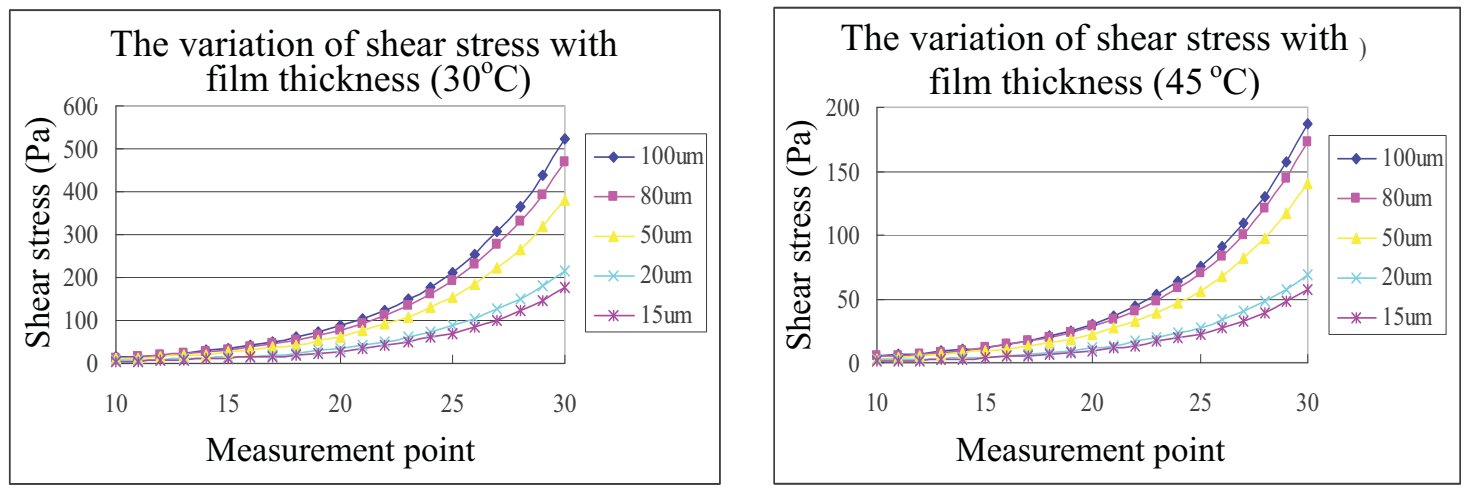

Fig. 5 The variation curves of shear stress under various oil film thickness
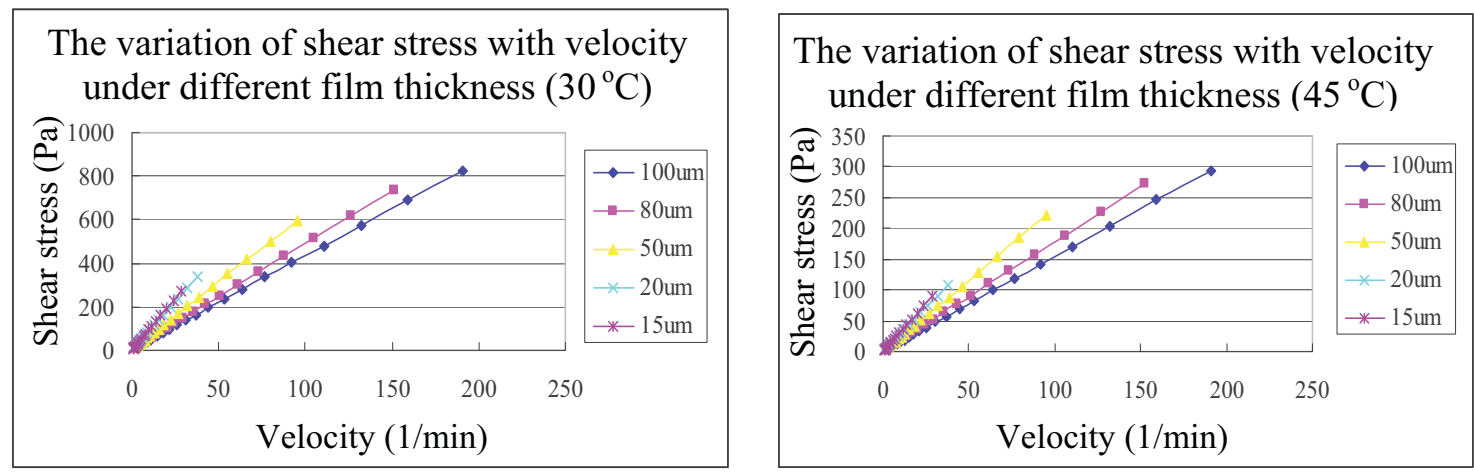

Fig. 6 The variation curves of shear stress with roll speed under various oil film thickness

The Variation of Shear Stress with Roll Velocity at Different Film Thickness. As shown in Fig.6, the lubricating oil with higher viscosity will produce higher shear stress due to oil flow, and the shear stress is generally higher under the thin film thickness during the lower velocity range. Although the shear stress of oil film increases with the roll velocity, the full film can be maintained only under thicker oil film thickness. However, the thinner film could rupture at higher roll velocity. So, the variation range that the shear stress varies with roll velocity under the thin film thickness seems much shorter than that under the thick film. 


\section{Summary}

The effects of shear stress on different oil film layer have been analyzed. The circumferential shear stress on contact surfaces increases rapidly with roll velocity, the axial shear stress of oil film is only related to pressure flow, and increases with roll velocity. Meanwhile, the axial shear stress on the contact surfaces displays the asymmetric feature along the cross section of axial center, and the shear stress on roll surface has the same value as that on bearing surface with opposite direction. Moreover, Germany-made Anton Paar MRD-301 was used to measure the lubricating oil properties, the distribution laws on the variation of viscosity with shear stress, roll velocity and temperature have been proved to be consistent with the theoretical results, which could provide references for further research on lubricating performance of oil film bearing in large-scale mill.

\section{Acknowledgements}

The authors would like to express their appreciation to the support of the project of the National Natural Science Foundation (50575155), Shanxi Generalization Project of Science and Technology Achievements (2007071071), and Shanxi Overseas Scholarship Fund (20081071).

\section{References}

[1] S.Z.Wen, P.R.Yang: Elasohydrodynamics Lubrication (Tsinghua University Press, China 1992).

[2] X.Q. Guo, S.Q. Li. Modern Large-scale Mill Oil-film Bearing (Machine Press, China 1992).

[3] Z.Y. Jiang, A.K. Tieu. J. Tribol. Int. Vol. 37 (2004), p. 185

[4] G.Z. Ding. J. Taiyuan Sci \& Tech Univ. Vol. 25 (2004), p. 1

[5] J. M. Wang, Q. X. Huang, C.J. Zhao and J. B. Yao: Key Eng. Mater. Vol. 324-325(2006), p. 323

[6] J.M. Wang, Q.X. Huang, in: The Proceeding of the $1^{\text {st }}$ International Symposium on Digital Manufacture, China, (2006), p. 186 
Advances in Abrasive Technology XII

10.4028/www.scientific.net/AMR.76-78

The Effects of Shear Stress on the Lubrication Performances of Oil Film of Large-Scale Mill Bearing 10.4028/www.scientific.net/AMR.76-78.713

\section{DOI References}

[3] Z.Y. Jiang, A.K. Tieu. J. Tribol. Int. Vol. 37 (2004), p. 185

doi:10.1016/S0301-679X(03)00049-5

[5] J. M. Wang, Q. X. Huang, C.J. Zhao and J. B. Yao: Key Eng. Mater. Vol. 324-325(2006), p. 323

doi:10.4028/www.scientific.net/KEM.324-325.323 